\title{
Women's empowerment in Indian agriculture: does market orientation of farming systems matter?
}

\author{
Soumya Gupta ${ }^{1,2}$ - Prabhu L. Pingali ${ }^{3} \cdot$ Per Pinstrup-Andersen ${ }^{4}$
}

Received: 13 July 2016 / Accepted: 2 November 2017 / Published online: 13 November 2017

(C) The Author(s) 2017. This article is an open access publication

\begin{abstract}
This paper studies the relationship between the Women's Empowerment in Agriculture Index (WEAI) and market orientation of farm production in India. This is the first time that the WEAI has been used in an Indian agricultural context and the first time that it is being associated with market orientation. We used data on 1920 adults from 960 households in the Chandrapur District of Maharashtra and classified the households into three groups-(1) landless, (2) foodcropping, and (3) cash-cropping - that reflect increasing degrees of market orientation. We foind that women are disempowered in two major domains of agriculture-resources (access and decision-making) and leadership (group membership). A multivariate regression analysis shows that empowerment levels were significantly higher for women belonging to cash-cropping households, followed by foodcropping and landless households. Other significant determinants of empowerment scores are women's age, education level, and household-level characteristics such as ownership
\end{abstract}

Electronic supplementary material The online version of this article (https://doi.org/10.1007/s12571-017-0737-4) contains supplementary material, which is available to authorized users.

Soumya Gupta

sg672@cornell.edu

1 Tata-Cornell Institute for Agriculture and Nutrition, Cornell University, Ithaca, NY, USA

2 Present address: Technical Assistance and Research for Indian Nutrition and Agriculture, Tata-Cornell Institute for Agriculture and Nutrition, Cornell University, New Delhi, NY, India

3 Charles H. Dyson School of Applied Economics and Management, Tata-Cornell Institute, Cornell University, Ithaca, NY, USA

4 Charles H. Dyson School of Applied Economics and Management, Cornell University, Ithaca, NY, USA of livestock, irrigation, electricity, and amount of land owned. As a secondary objective of this paper, we find that women's empowerment in agriculture was also significantly associated with their decision-making in non-agricultural domains. The strong relationship between market orientation and empowerment levels suggests that linking women to markets can be a pathway to enhancing their empowerment in agricultural domains. Ensuring their ability to make decisions related to the cultivation of crops and their participation in the sale of those crops, with associated income, can be some areas for which relevant policies can be designed, tried, and studied.

Keywords Women's empowerment $\cdot$ Agriculture $\cdot$ India Farming systems $\cdot$ Market orientation

\section{Introduction}

Women account for $43 \%$ of the agricultural labor force in developing countries and slightly more than $30 \%$ in South Asia and India (FAO 2011). However, their access to productive resources (such as land and livestock), inputs (fertilizers and improved seeds), and services (credit, extension) for agriculture reflects a "gender gap" that most often is rooted in social norms specific to a given geography and culture. It is in the same context that women carry out many responsibilities within households, in addition to agricultural labor (e.g., caregiving of children and the elderly, fetching water and fuel, and tending to domestic chores) (FAO 2011). This disparity in access to productive resources, inputs, and services may result in women's lower agricultural productivity and less control of household income and decisions, as well as barriers to adoption of new technologies or practices. The nature of the farming systems in which women practice agriculture may be quite important for determining the extent of the disparities observed through this gender gap. The 
diversity of crops and animals raised, farm management practices, the orientation of farm output (e.g., for subsistence, commercial, or contract use), and the type of labor employed may all play a role (FAO 2011). However, very little research has systematically examined the connection between farming systems and the status of women, that is, their level of empowerment relative to men, specifically in the domain of agriculture.

Women's empowerment has traditionally been studied in terms of indicators, such as education (Haddad 2000; Smith and Haddad 2000; Berti et al. 2004), control over income (Berti et al. 2004; Leroy et al. 2008; Arimond et al. 2011; Pinstrup-Andersen and Watson 2011), gender of household head (Kennedy and Peters 1992; Rogers 1996), and control over assets at the time of marriage (Quisumbing and Maluccio 2003). Smith et al. (2003) used indirect or proxy indicators to construct two measures of women's empowerment-women's decisionmaking power and societal gender equality. They concluded that women's status in South Asia is the lowest relative to subSaharan Africa and the Latin America and Caribbean regions. Similarly, the Global Gender Gap Index (GGGI) developed by the World Economic Forum is a measure of the gap between women's and men's achievements in four broad outcomes: health, education, economic participation, and political empowerment (WEF 2014). The GGGI (and each of its subindices) range from 0 (inequality) to 1 (equality). In 2014, India's overall score was 0.64 , and it ranked 114 out of a total of 142 countries. Cunningham et al. $(214,215)$, as part of their literature review, used three broad domains of empowerment: (1) social support, (2) workload and time, and (3) autonomy and control over income/other resources, which constitute "more direct" measures of empowerment, in contrast to "proxy" measures such as education and age at marriage.

In contrast to measures of status or bargaining power, as described previously, Kabeer (1999) viewed empowerment as a process that enables individuals to "exercise choice." This notion of empowerment focuses on three interrelated dimensions: resources, agency, and achievements. The Women's Empowerment in Agriculture Index (WEAI) particularly focuses on the agency (or decision-making) aspect of empowerment. Before the WEAI, indicators of empowerment also did not explicitly focus on decision-making in multiple domains in agriculture. Moreover, they rarely compared empowerment of men and women in the same household. They are also limited in their decomposability by domain, region, and/or gender to identify key constraints to empowerment. It is against this backdrop that the recently developed WEAI provides an improvement over the existing indicators (Alkire et al. 2013a, b). The WEAI was developed by the International Food Policy Research Institute (IFPRI), Oxford Policy and Human Development Initiative (OPHI), and the United States Agency for International Development (USAID), and is a direct measure of multidimensional deprivations that women and men face in the domain of agriculture. Its focus on different dimensions in agriculture accounts for the fact that individuals face multiple deprivations that can be interconnected and/or experienced simultaneously (joint distribution of deprivations), so that focusing on any one deprivation in isolation would result in a partial analysis of deprivations at best. The decomposability of the index allows us to move beyond identifying who is or is not disempowered to also identify which indicators contribute to disempowerment. Results from the WEAI baseline surveys (Malapit et al. 2015) in USAID's "Feed the Future" countries indicate that the index has been used in surveys, so far in two countries in South Asia-Bangladesh and Nepal.

The WEAI focuses on women's decision-making and access to resources in multiple domains of agriculture. These would differ based on the type of agricultural activities that a household is participating in-for example, crop cultivation or livestock management - as well as the nature of those agricultural activities - for example, if crop cultivation is for subsistence or for sale in the market. We would expect empowerment levels to differ as the nature of agricultural activities changes. The WEAI has been studied with respect to nutritional outcomes in Nepal (Malapit et al. 2015; Cunningham et al. 2015) and food security outcomes in Bangladesh (Sraboni et al. 2014). However, although these studies account for production diversity and area of cultivable land, respectively, the existing literature has not accounted for the market orientation of farm production. Two households with the same production diversity or the same area of cultivable land can reflect two very different resource-base situations in terms of access to, and decision-making about, productive resources. For instance, although two households may be producing the same number of crops, the market orientation of those crops can differ based on land ownership, area under cultivation, access to irrigation, and other factors.

In this paper, we attempt to bridge the gap by focusing on the relationships between market orientation of agricultural households and women's empowerment across 960 households and among 1920 adults in the Chandrapur District of Maharashtra, India. To our knowledge, this is the first time the WEAI has been analyzed in this manner in general, and in India, in particular. The primary objective of this research is to assess and compare women's empowerment status in agriculture for three groups of households - those that are landless, those that cultivate food crops primarily for subsistence, and those that cultivate cash crops that are sold in the market. These three groups will be described in detail in Section 2.3.1. We also compare empowerment of women with that of men in the same household and identify the key drivers of disempowerment for both genders. Additionally, we assess how results from the WEAI compare and contrast with traditional proxy indicators of empowerment, such as age, education, and women's decision-making in nonagricultural domains. We believe this body of work helps to fill the knowledge gap around issues of women's empowerment and market orientation, especially for India. 


\section{Material and methods}

\subsection{Data sources}

Primary data for this study was collected in the Chandrapur district of Maharashtra, India, over the period June 2013March 2014. Formative research was carried out from JuneOctober 2013 to inform the design and development of survey tools. This was followed by the household survey that was implemented in January-March 2014.

The district lies in Eastern Maharashtra and was selected for this study because of the variation in cropping patterns that are present there. The western half of Chandrapur district is characterized by cotton and soybean cultivation (similar to the rest of the Vidarbha region of Maharashtra), while the eastern half is predominantly under paddy/rice cultivation (GOM 2000). Our study focused on production data related to the monsoon season (kharif) in 2013 and the winter season (rabi) 2014. If a household did not undertake cultivation in rabi 2014, or had not harvested the crops for rabi 2014 at the time of the survey, then they were asked to recall production activities of rabi 2013.

A total of 960 households, across 24 villages, were selected in the district based on a two-stage sampling design. The sample size of 960 households was calculated using the WEAI as the primary outcome variable. Based on the initial pilot results of the WEAI (Alkire et al. 2013a), we assumed a difference in mean empowerment levels between two groups of 0.10 , a standard deviation of $0.2,99 \%$ confidence interval (alpha of 0.01 ), and power of 0.97 . This gave us a sample size for each group of 159. After incorporating a design effect of 2, we reached a sample size of 318 per group. Based on the three blocks identified during the formative research phase, a total of 320 households per block were accordingly selected. The total sample size is then 960 households. Since both the index man and woman from each household were interviewed, the total number of survey respondents was 1920 adults.

We used a two-stage sampling strategy for the selection of villages and households. In the first stage, the selection of villages was based on the probability proportional to population size sampling method. This ensures that variation in total populations across villages were taken into account in the sampling of villages. In the second stage, selection of households from each village was done randomly using a random number generator. For both stages, complete village- and household-level lists were generated after triangulation of available lists from the village-, block-, and district-level government office. In each household, an index man and woman were interviewed. The term "index" in this paper is used to identify the primary male and female respondent in each household, based on the survey inclusion/exclusion criteria. For the index women, there were two main inclusion criteria: they belonged to the reproductive age group of 15-49 years old and were neither pregnant nor lactating. If two (or more) women in the household met these criteria then the youngest was considered for the survey. The index men were included in the survey if they (and their household) had been residing in the village for 2 years preceding the data collection. In all cases but two, the index man and woman were spouses - in the remaining two they were a mother-son pair where the mother was a widow and the son was unmarried. The index woman and her spouse, the index man, however, need not correspond to the household head and his or her spouse. For instance, a given household could have a son living with both his parents and his wife. If his mother did not fall in the reproductive age group (i.e., was older than 49 years), then we considered the son and his wife to be the index man and woman, respectively (provided the latter was between 15 and 49 years). "Household" here refers to the total number of people who share a kitchen (or cooking stove, commonly known as the "chulha"). Households were not excluded based on amount of land owned. Migration did not influence the identification of index men and women since the data collection for this study coincided with the harvest period, and therefore migration if any would have occurred in the post-harvest period.

Household-level data was collected from the index man in the following areas: (1) household composition; (2) socioeconomic status; (3) agricultural practices and land use; (4) livestock; (5) nonfarm employment; (6) food availability and access; and (7) empowerment in agriculture. Individual-level data was collected from the index woman in the following areas: (1) agricultural employment; (2) nonfarm employment; (3) semi-quantitative food frequency questionnaire; (4) home gardens; (5) household chores; (6) water, sanitation, and hygiene; (7) health (reproductive history, anemia, health-seeking behavior); (8) child care; and (9) empowerment in agriculture. The WEAI module was modified according to the specifics of agriculture in the Chandrapur District and translated from English to Marathi. The changes included the exclusion of fisheries, inclusion of participation in collection of forestbased produce, and a change in the types of community groups and credit sources present. These changes were arrived at after conducting preliminary focus group discussions and in-depth interviews across the district to understand better the local cropping patterns and allied agricultural activities in which households engage. ${ }^{1}$

\footnotetext{
${ }^{1}$ The questionnaire for this study was designed by Soumya Gupta and was translated into Marathi by Pramod Bahulekar, a social scientist at the MGIMS, India. A team of 20 enumerators and 2 supervisors were trained over a period of 10 days on the use of the computer software developed for the household survey questionnaire, using in-class and in-field sessions. The training was conducted with support from the Department of Community Medicine at MGIMS
} 


\subsection{Compliance with ethical standards}

This research work was funded by the Tata-Cornell Institute for Agriculture and Nutrition (TCI) at Cornell University and was approved by Cornell's Institutional Review Board. Ethical approval was also obtained from the Mahatma Gandhi Institute of Medical Sciences (MGIMS) in Maharashtra, India. Informed consent was recorded verbally from all individual participants included in this study. Verbal consent was chosen over written consent, as the survey was computer-based. Responses to the informed consent process were recorded accordingly in the survey software.

\subsection{Construction of key variables}

\subsubsection{Classification of households into farming systems based on market orientation}

The Food and Agriculture Organization of the United Nations (FAO) defines a farming system as "a population of individual farm production systems that have broadly similar resource bases, enterprise patterns, household livelihoods and constraints, and for which similar development strategies and interventions would be appropriate." ${ }^{2}$ We use the term "farming system" to identify three categories of households, using data on two aspects of agricultural production-land ownership and market orientation of crops harvested.

Two broad types of households are considered from the point of view of land ownership: households that did not own any land (landless), and households that cultivated crops on land owned and/or rented by them. Households that owned land but chose not to use it for crop cultivation were excluded from the data analysis $(n=22)$. This was done because we expected these households to display very different behavior/ decision-making from households that were truly landless, since the former would still have access to more resources, such as household income and assets, than the latter.

For the purpose of this research, market orientation for a given household was determined by the extent to which marketable surplus was produced in any cropping season. Market orientation of crop harvest was based on harvest data for the 2013-2014 agricultural season. We focused on cultivation, production, and sale of crop harvest mainly in the monsoon season rather than the winter season. This is because the monsoon season is the main crop cultivation season; it lasts longer than the winter season; and more households cultivate crops in the monsoon season than the winter (due to lack of irrigation facilities in the winter). The main monsoon season (kharif) crops in the region are cotton, soybean, sorghum, and paddy rice while the winter season (rabi) is characterized by the cultivation of wheat, gram (chickpea), and a local variety of

\footnotetext{
${ }^{2}$ http://www.fao.org/farmingsystems/description_en.htm
}

lentil (lakori). Crop cultivation in the winter season, if it is undertaken at all, is typically on a small proportion of the total cultivable land, and the harvest is kept for home consumption.

Based on the land ownership and marketable surplus, we categorized households into three groups with different degrees of market orientation: (1) cash-cropping households, (2) food-cropping households, and (3) landless households. Cash-cropping households are those that cultivated at least one of two cash crops: cotton or soybean. Food-cropping households primarily grow a monoculture of rice in the monsoon season. The third group consists of the landless households that do not own any land of their own but may choose to work solely as agricultural laborers for a daily wage. We do not distinguish which type(s) of crop(s) these individuals work on. This is done because, based on formative research, we know that they are paid a per day rate in cash, irrespective of whether they work as day laborers for food crops or cash crops. Landless households are included in this analysis, since their market orientation is different from land-owning households. These households are not directly involved in the decisions surrounding cultivation and sale of crops; however, landless households do engage in allied activities like livestock rearing and collection of forest produce. This is relevant to the WEAI, since the empowerment index focuses not just on decisions around crop cultivation but also other allied activities, as well as household characteristics such as asset ownership, access to credit, and time use. Thus, we assert that the landless group presents itself as a group distinct from cashcropping or food-cropping households.

Key characteristics for each group are presented in Table 1. Here we see that the average number of crops cultivated and area of plots owned by respondents in cash-cropping households is double that in the food-cropping households. Table 1 also suggests that the degree of market orientation increases as we move from landless households to food-cropping and then to cash-cropping households. Data on crop use indicate that cash-cropping households sell a larger proportion (almost all) of their harvest and benefit from a higher value of sale, as compared to the food-cropping households. From the data available on crop use in Table 1, we know that cashcropping households sell practically all of the cotton and soybean, and less than $30 \%$ of any winter food crop that they may cultivate. Food-cropping households sell about $40-50 \%$ of their crop. Furthermore, the total value of sales (from all crops cultivated) of cash-cropping households is 21 times that of food-cropping households on average.

Descriptive statistics from Table 1 also indicate that $60-70 \%$ of the households have a home garden (that is, cultivation of seasonal fruits and vegetables in the homestead or around the kitchen) in all three groups. Landless households by definition do not cultivate any crops on owned land (however, they do work as agricultural wage labor on land owned by others) and have the lowest 
Table 1 Household- and individual-level characteristics of farming systems identified for this study

\begin{tabular}{|c|c|c|c|c|}
\hline & Landless & Food & Cash & All \\
\hline Number of households & 183 & 328 & 427 & 938 \\
\hline $\begin{array}{l}\text { Crops harvested }{ }^{\mathrm{a}, \mathrm{s} 1} \\
\text { (range) }\end{array}$ & 0 & $1.2(1-4)$ & $2.5(1-7)$ & 1.6 \\
\hline \multicolumn{5}{|l|}{$\begin{array}{l}\text { (range) } \\
\text { Proportions sold }\end{array}$} \\
\hline Cotton & $\mathrm{N} / \mathrm{A}$ & $\mathrm{N} / \mathrm{A}$ & 0.90 & 0.90 \\
\hline Soybean & N/A & N/A & 0.95 & 0.95 \\
\hline Sorghum & N/A & 0.06 & 0.22 & 0.20 \\
\hline Paddy/rice & N/A & 0.40 & 0.20 & 0.33 \\
\hline Gram & $\mathrm{N} / \mathrm{A}$ & 0.50 & 0.30 & 0.32 \\
\hline Wheat & $\mathrm{N} / \mathrm{A}$ & N/A & 0.11 & 0.09 \\
\hline Lakori & $\mathrm{N} / \mathrm{A}$ & 0.40 & 0.22 & 0.32 \\
\hline Proportion of total harvest sold & $\mathrm{N} / \mathrm{A}$ & 0.387 & 0.570 & 0.490 \\
\hline Total value of sale (in USD) $)^{\mathrm{b}, \mathrm{s} 1}$ & 0 & 316.95 & 6654.9 & 3140.3 \\
\hline Presence of home-garden ${ }^{\mathrm{c}, \mathrm{s} 2}$ & $64.5 \%$ & $58.8 \%$ & $73.3 \%$ & $66.5 \%$ \\
\hline Total livestock units ${ }^{\mathrm{d}, \mathrm{s}}$ & 0.21 & 0.62 & 0.46 & 0.46 \\
\hline Double cropping households ${ }^{\mathrm{c}, \mathrm{e}}$ & $\mathrm{N} / \mathrm{A}$ & $13.1 \%$ & $19.6 \%$ & $13.5 \%$ \\
\hline Access to irrigation $^{c}$ & $\mathrm{~N} / \mathrm{A}$ & $40.5 \%$ & $33.2 \%$ & $28.4 \%$ \\
\hline Number of own plots ${ }^{\mathrm{a}, \mathrm{s}}$ & $\mathrm{N} / \mathrm{A}$ & 1.14 & 1.14 & 0.92 \\
\hline Area of own plots (in acres) $)^{a, s}$ & $\mathrm{~N} / \mathrm{A}$ & 2.6 & 5.2 & 3.2 \\
\hline \multicolumn{5}{|l|}{ Agricultural wage labor ${ }^{\mathrm{c}, \mathrm{s} 2}$} \\
\hline Women & $94.5 \%$ & $84.6 \%$ & $67.6 \%$ & $78.6 \%$ \\
\hline Men & $92.1 \%$ & $76.4 \%$ & $55.2 \%$ & $69.7 \%$ \\
\hline \multicolumn{5}{|l|}{ Off-farm employment ${ }^{\mathrm{c}, \mathrm{s} 2}$} \\
\hline Women & $23.5 \%$ & $28.3 \%$ & $9.4 \%$ & $18.8 \%$ \\
\hline Men & $40.9 \%$ & $39.9 \%$ & $19.6 \%$ & $30.9 \%$ \\
\hline Access to electricity ${ }^{\mathrm{c}}$ & $80.9 \%$ & $92.1 \%$ & $91.1 \%$ & $89.4 \%$ \\
\hline Household size $^{\mathrm{a}}$ & 4.25 & 4.61 & 4.79 & 4.62 \\
\hline Disadvantage caste $^{\mathrm{c}}$ & $97.8 \%$ & $99.7 \%$ & $99.5 \%$ & $99.3 \%$ \\
\hline Age of index woman (years) & 33.72 & 34.01 & 33.16 & 33.57 \\
\hline Years of education of index woman & 4.46 & 6.06 & 5.98 & 5.71 \\
\hline
\end{tabular}

${ }^{\text {a }}$ Mean values for each farming system

${ }^{\mathrm{b}}$ An average exchange rate of INR 62 to USD 1 is used (www.X-rates.com)

${ }^{\mathrm{c}}$ Proportion of households

${ }^{\mathrm{d}}$ Mean values for Total livestock units (TLU) owned by each household. TLU was calculated using conversion factors outlined for India (FAO 2005): cattle (cows, oxen) -0.50 , buffalo -0.50 , sheep and goats -0.10 , poultry (chicken, duck) - 0.01. Conversion units for donkey — 0.5 — were obtained from (http://www.lrrd.org/lrrd18/8/chil18117.htm)

${ }^{\mathrm{e}}$ Households that cultivated a crop in both the monsoon (kharif) and winter (rabi) cropping seasons

${ }^{\mathrm{s} 1}$ Non-parametric Kruskal Wallis tests indicate differences between farming systems are significant (see text for details)

${ }^{\text {s2 }}$ Odds ratios indicate differences between farming systems are significant (see text for details) number of livestock units on average- - half of those found in cash-cropping households and a third of those found in food-cropping households. More than $90 \%$ of men and women in the landless group work as agricultural wage laborers. Rates of off-farm employment are lower in the cash-cropping group relative to the other two groups.

Non-parametric Kruskal Wallis tests indicate that there are significant differences ( $p$ value 0.000 ) between the three groups with respect to the total number of crops harvested, total number of plots owned, total value of crop sales, and area of owned plots. More specifically, these four characteristics are significantly lower in the food-cropping households, relative to the cash-cropping households ( $p$ value $0.00,0.012$, 0.000 , and 0.000 , respectively).

Total livestock units owned by households in the foodcropping group are significantly higher than in the landless group ( $p$ value 0.001 ) and cash-cropping group ( $p$ value 0.000 ). Odds ratios indicate that the odds of a home garden being present in cash-cropping households are significantly higher, relative to the landless group (OR 1.5, $p$ value 0.03 ). 
Men (OR 0.35, $p$ value 0.00 ) and women (OR 0.34, $p$ value 0.00 ) in cash-cropping households are less likely to engage in off-farm employment, relative to those in the landless group. The odds for participation of men and women in agricultural wage labor in both food and cash-cropping households are lower than for those in the landless group (OR, $p$ values in the food-cropping group are $0.27,0.00$ for men and 0.32 , 0.003 for women; OR, $p$ values in the cash-cropping group are $0.10,0.00$ for men and $0.12,0.00$ for women).

\subsubsection{Women's Empowerment in Agriculture Index}

The WEAI is made up of two subindices. These are the five domains of empowerment (5DE) subindex and the gender parity subindex (GPI). The 5DE subindex looks at women's empowerment in five main domains-production, resources, income, leadership, and time. A brief description of what it means for an individual to have adequate achievements in each indicator, together with its respective weight, is outlined in Table 2. The GPI subindex of the WEAI is a measure of intrahousehold inequality. On the one hand, it measures the relative parity in 5DE scores of the index woman and index man in the same household. On the other hand, it also accounts for the gap in empowerment between men and women for households in which there is no gender parity. The WEAI is also calculated at the aggregate level (that is, for each farming system) and is arrived at as a weighted sum of the $5 \mathrm{DE}$ and GPI:

$W E A I=0.9 \times 5 D E+0.1 \times G P I$

Each of the three: 5DE, GPI, and WEAI range from 0 to 1 as adequacy/parity/empowerment levels improve. For the $5 \mathrm{DE}$ score, a threshold of 0.80 is set for identifying empowerment/adequacy.

The WEAI is based on the Alkire-Foster methodology (Alkire et al. 2015), which focuses on constructing multidimensional poverty measures by (1) using a "dual-cutoff' to identify and count "poor" people; and (2) aggregation based on an extension of the Foster-Greer-Thorbecke (FGT) measures to multidimensional space. Alkire et al. (2013a, b) discussed in detail the application of this methodology, specifically with respect to the WEAI. In the appendix to this paper, we present a brief summary of their methodology that focuses on the construction of the 5DE and GPI subindices with respect to two measures of interest: the Adjusted Headcount Ratio (M0) and the Adjusted Poverty Gap (M1). The M0 is used to arrive at the 5DE subindex, whereas the M1 is used to construct the GPI subindex.

The computation of the 5DE score for this study differs from the original in two respects. The original WEAI includes two attributes for group membership: (1) whether or not the individual is a member of any group, that is "membership," and (2) whether or not the individual is an "active member" of the group in terms of attending meetings, holding a position, such as president or secretary. The subindicator for the group in this paper is based on membership alone. This is to avoid a massive drop in the number of observations ( $n=1216$ missing, including both men and women) due to missing data on "active" group membership. We expected that, by not accounting for "active" group membership, our results were likely to result in an overestimation of women's empowerment, specifically in the group membership subindicator, since it is likely that there would be fewer women who would meet the criteria for belonging to a group and playing an active role in it. The subindicator for workload is based on time spent in "primary activities" alone. Data for time spent on "secondary" activities was not collected. ${ }^{3}$ Individual timeuse data was not dropped if it summed to less than $24 \mathrm{~h}$ $(n=1545)$, again to avoid a drop in the number of observations. We expect that this will result in an underestimation of women's workload, since it is likely that hours spent on various activities will increase if secondary activities were included since by definition time spent on the latter is on activities that are occurring simultaneously with the primary time-use activities. .

\subsection{Data analysis}

The 5DE, GPI, and WEAI scores are computed for the total sample and for each of the three farming systems. To facilitate comparisons of the 5DE and GPI subindices across farming systems, we used the following individual-level variables:

- Censored empowerment score equals 1 if the individual is empowered and equals the weighted adequacy score (continuous) if the individual is disempowered. This is calculated for each individual and at the aggregate level is a component of the $5 \mathrm{DE}$ subindex.

- Disempowerment status equals 1 if the individual is disempowered, 0 if empowered. This is derived from the individual censored empowerment scores. Women's disempowerment status $=1(0)$ if the censored empowerment score $<1(=1)$.

- Parity gap equals the gap in empowerment (continuous) of women, relative to men; it takes on a score of 1 if a woman lacks parity, and equals 0 if a woman has gender parity. The parity gap is based on the empowerment scores of men and women.

\footnotetext{
${ }^{3}$ Personal communication with the IFPRI staff at the time of data analysis indicated that this is not expected to influence the overall workload indicator. Moreover, updated questionnaires for the Abbreviated WEAI do not ask for secondary time-use activities.
} 
Table 2 Adequacy characteristic and weights for five domains of empowerment (Alkire et al. 2013a, b)

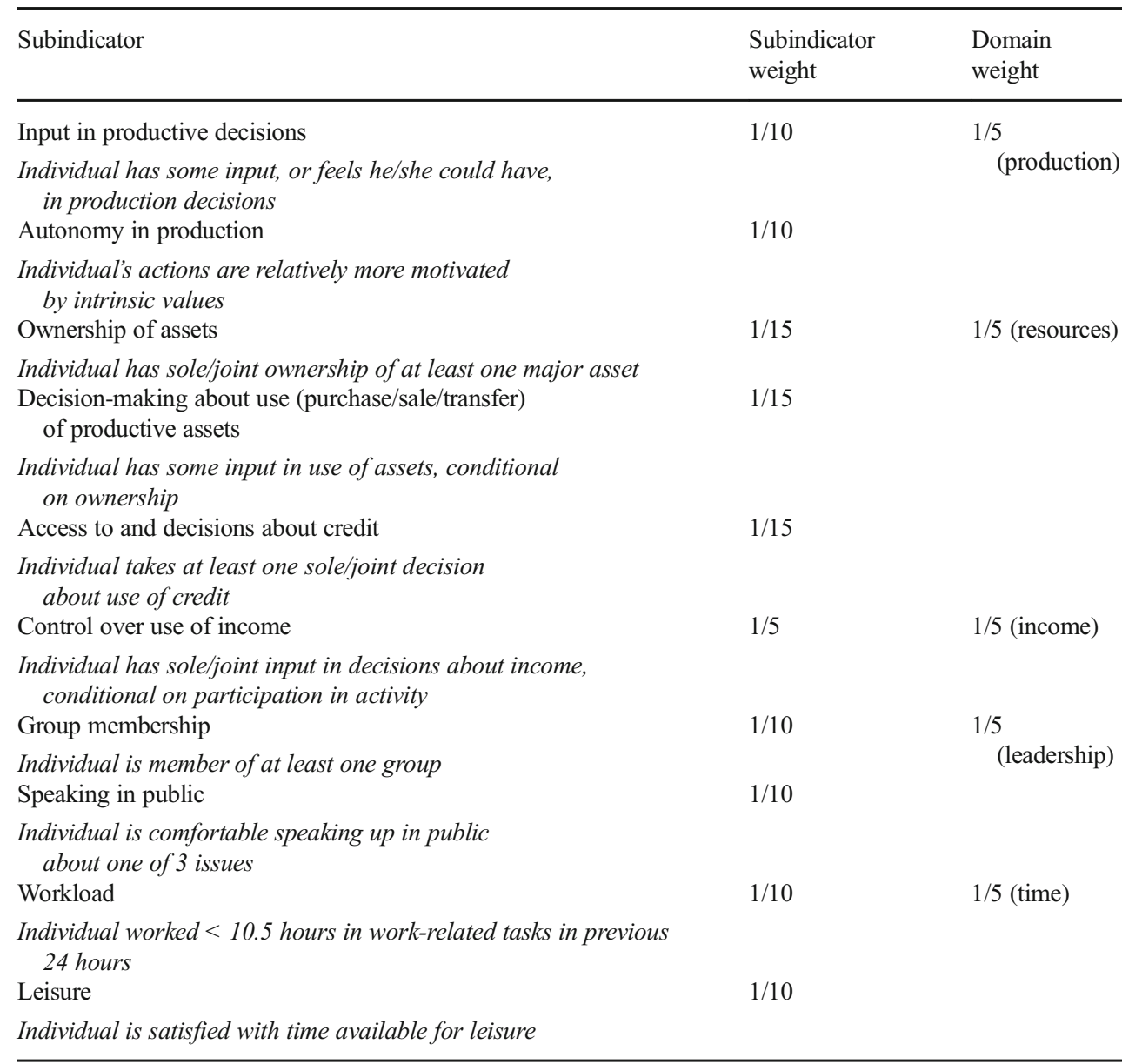

- Parity status equals 1 if woman has gender parity, 0 if otherwise. This is derived from the parity gap variable. Parity status $=1(0)$ if the parity gap for women $=0(>0)$.

We decompose the 5DE score to identify disempowerment across subindicators, as well as to identify the absolute and percentage contribution of each subindicator (and, therefore, each domain) to the overall disempowerment score. Subindicators with contributions greater than their weight indicate "that the disempowered are more inadequate in this indicator than in others" (Alkire et al. 2013a, p. 78).

Descriptive statistics on headcounts and aggregate scores are presented for the total sample and each farming system. Difference in empowerment scores and average empowerment gap across farming systems were tested for using nonparametric Kruskal Wallis. Odds ratios were used to study any differences in the odds of being disempowered and of women lacking gender parity at the $20 \%$ cutoff. Key drivers of disempowerment for men and women, in each of the three farming systems, were also identified.

A multivariate regression analysis is included to test the relationship between women's empowerment in agriculture and the market orientation of the farming system in which they operate (Eq. 2). Women's censored empowerment score is used as the dependent variable. Market orientation of the farming system is based on the categorization of households into three farming systems ("farmsys"). We controlled for individual-level characteristics (variable "Ind" in Eq. 2 is a vector of individual characteristics) such as the woman's age and age squared (in years) and education level (categorical variable, ranging from 1 to 4 for education levels: primary, middle, high school, college, and no education). Householdlevel characteristics (variable " $\boldsymbol{H} \boldsymbol{H}$ " in Eq. 2 is a vector of household characteristics) such as access to irrigation, total area of owned plots, total livestock units, access to electricity, household size, and caste were also controlled for. We recognize that this formulation does not address endogeneity between farming systems and both access to irrigation and area of owned plots.

$$
\begin{aligned}
\text { Empowerment }= & \alpha_{0}+\alpha_{1} \text { farmsys }+\boldsymbol{\alpha}_{2} \text { Ind }+\alpha_{3} \boldsymbol{H} \boldsymbol{H} \\
& +\varepsilon_{0}
\end{aligned}
$$

Additional logistic regressions were also carried out to test the relationship between women's empowerment in 
agriculture and their ability to take decisions regarding nonagricultural activities. In Eqs. 3 and 4, we look at the following set of activities ("non-ag decision") as the outcome variable: minor household expenditures, family planning, food preparation, seeking healthcare, child feeding, and visiting their mothers. Equation 3 focuses on women's ability to take decisions regarding the already mentioned activities. Equation 4 focuses on women's autonomy in decision-making. For both of these equations, the dependent variable is binary in nature. The independent variable in both equations refers to women's censored 5DE scores ("Emp ag"). In both the equations, we also control for individual-level characteristics (vector "Ind" in Eqs. 3 and 4), such as woman's education level and age difference between the index man and woman, as well as household-level characteristics (vector "Household" in Eqs. 3 and 4), such as caste and household size.

$$
\begin{aligned}
\text { Non-ag decision }= & \alpha_{0}+\alpha_{1} \text { Emp }_{a g}+\boldsymbol{\alpha}_{2} \text { Ind } \\
& +\boldsymbol{\alpha}_{3} \text { Household }+\epsilon_{0}
\end{aligned}
$$

Non-ag autonomy $=\alpha_{0}+\alpha_{1} E_{\text {Emp }}+\alpha_{2}$ Ind

$$
+\alpha_{3} \text { Household }+\varepsilon_{0}
$$

\section{Results}

\subsection{WEAI and key drivers of disempowerment of women across farming systems}

Table 3 reports results for the WEAI and its two subindicators (5DE and GPI). The WEAI score for the total sample is 0.785 . We find that $36.6 \%$ of the women in the sample are empowered and have adequacy in $77.0 \%$ of the 10 subindicators considered. The $63.4 \%$ of women who are not empowered are adequate in $64.0 \%$ of the weighted indicators, on average. The GPI score for the sample is 0.9 . Parity is enjoyed by $64.5 \%$ of the women, which means $35.5 \%$ of the women do not-for them, the average gap in empowerment levels they face is $22.3 \%$. Across the three different farming systems, the WEAI is lowest in the landless group (0.7) and highest in the cash-cropping group (0.8).

Unlike women in cash-cropping households, the women in the landless and food-cropping households are, on average, disempowered in the five domains of agriculture $(5 \mathrm{DE}$ score $<0.80)$. There are significant differences in women's censored 5DE scores between farming systems ( $p$ value 0.000$)$. Women in the landless group are significantly more disempowered in the five domains of agriculture as compared to women in food-cropping ( $p$ value
$0.002)$ and cash-cropping households ( $p$ value 0.0001$)$. In fact, the odds of a woman being disempowered in the food- (OR $0.6, p$ value 0.03 , CI $0.4-0.95$ ) and cashcropping groups (OR $0.43, p$ value 0.00 , CI $0.3-0.65$ ) are significantly lower, relative to the landless group. There are, however, no significant differences in the gender parity gap faced by women in the three farming systems ( $p$ value 0.79 ).

We disaggregated the 5DE subindex into its component subindicators to identify the key drivers of women's disempowerment in agriculture. Figure 1 shows the proportions of women disempowered in each subindicator for each farming system. The majority of women, in all three groups, are unable to make decisions regarding use of assets, lack access to credit (and the ability to make decisions regarding its use), and are not members of any community group. The odds of women being disempowered in these three areas are significantly higher in the landless group, as compared to the food- and cash-cropping groups (see Table 1 in supplementary materials). The cashcropping group has significantly higher odds of women facing an excessive burden of work, relative to the foodcropping and landless groups. The subindicators that account for a large proportion of disempowered women in all three farming systems - decision-making, credit, group membership, and workload-are also the subindicators that contribute the most to aggregate disempowerment scores. This can be seen in Fig. 2, wherein the total length of the bars reflects the total absolute contribution of the 10 subindicators to disempowerment of men and women in each farming system. The same four subindicators are also cause for concern, because each of their percentage contribution to total disempowerment of women (figure not shown) exceeds their individual weights $(6.6,6.6$, $10.0,10.0 \%$, respectively). This is true for all three farming systems. However, their relative importance is different within each farming system. Although group membership has the largest contribution to women's disempowerment in all three systems, the next largest contribution comes from different subindicators-decision-making and credit in the landless group, decision-making and workload in the food-cropping group, and workload in the cash-cropping group.

When the 10 subindicators are aggregated to the level of each domain of agriculture, we find that the results reported here indicate that women's disempowerment in agriculture is largely due their lack of access to, and decision-making about, productive resources, as well as due to a lack of leadership opportunities (see Fig. 3). These are also domains whose contribution to disempowerment is greater than their weight in the WEAI. While workload is an important contributor to women's disempowerment in the time-use domain, at an aggregate level, the contribution of the time-use domain is 
Table 3 Women's empowerment in agriculture index by farming system

\begin{tabular}{|c|c|c|c|c|c|c|c|c|}
\hline & \multicolumn{2}{|l|}{ Landless } & \multicolumn{2}{|l|}{ Food } & \multicolumn{2}{|l|}{ Cash } & \multicolumn{2}{|l|}{ Overall } \\
\hline & Female & Male & Female & Male & Female & Male & Female & Male \\
\hline \multicolumn{9}{|l|}{5 domains of empowerment subindex (5DE) } \\
\hline Disempowered headcount $^{\mathrm{a}}(\mathrm{H})$ in $\%$ & 75.8 & 69.2 & 65.7 & 31.6 & 57.4 & 23.2 & 63.4 & 34.3 \\
\hline Empowered headcount ${ }^{\mathrm{b}}(1-\mathrm{H})$ in $\%$ & 24.2 & 30.8 & 34.3 & 68.4 & 42.6 & 93.5 & 36.6 & 65.6 \\
\hline Average inadequacy score ${ }^{\mathrm{c}}(\mathrm{A})$ in $\%$ & 36.7 & 33.5 & 34.9 & 31.4 & 35.7 & 30.4 & 35.6 & 31.8 \\
\hline Average adequacy score ${ }^{\mathrm{d}}(1-\mathrm{A})$ in $\%$ & 63.3 & 69.5 & 65.1 & 68.6 & 64.3 & 71.7 & 64.4 & 68.2 \\
\hline Disempowerment index $(\mathrm{M} 0=\mathrm{H} \times \mathrm{A})$ & 0.28 & 0.23 & 0.23 & 0.10 & 0.20 & 0.07 & 0.23 & 0.11 \\
\hline 5DE index $(1-\mathrm{MO})$ & 0.72 & 0.77 & 0.77 & 0.90 & 0.80 & 0.93 & 0.77 & 0.89 \\
\hline No. of observations used & 156 & 145 & 318 & 306 & 427 & 427 & 880 & 879 \\
\hline Total observations & 183 & 183 & 328 & 328 & 418 & 416 & 938 & 938 \\
\hline$\%$ of data used & 85.2 & 79.2 & 96.9 & 93.3 & 97.8 & 974 & 93.8 & 93.7 \\
\hline \multicolumn{9}{|l|}{ Gender parity subindex (GPI) } \\
\hline Women without gender parity ${ }^{\mathrm{e}}\left(\mathrm{H}_{\mathrm{GPI}}\right)$ in \% & 37.3 & & 35.0 & & 35.2 & & 35.5 & \\
\hline Women with gender parity ${ }^{\mathrm{f}}\left(1-\mathrm{H}_{\mathrm{GPI}}\right)$ in \% & 62.7 & & 65.0 & & 64.8 & & 64.5 & \\
\hline Avg. empowerment gap ${ }^{g}\left(I_{\mathrm{GPI}}\right)$ & 23.4 & & 22.1 & & 22.1 & & 22.3 & \\
\hline Gender parity subindex $\left(\mathrm{GPI}=1-\mathrm{H}_{\mathrm{GPI}} \times \mathrm{I}_{\mathrm{GPI}}\right)$ & 0.91 & & 0.92 & & 0.92 & & 0.92 & \\
\hline No. of observations used & 126 & & 297 & & 403 & & 826 & \\
\hline Total observations & 183 & & 328 & & 427 & & 938 & \\
\hline$\%$ of data used & 68.8 & & 90.5 & & 94.4 & & 88.05 & \\
\hline \multicolumn{9}{|l|}{ Women's empowerment in agriculture index (WEAI) } \\
\hline WEAI $\left(0.9 \times 5 \mathrm{DE}_{\mathrm{F}}+0.1 \times \mathrm{GPI}\right)$ & 0.739 & & 0.785 & & 0.81 & & 0.785 & \\
\hline
\end{tabular}

${ }^{a}$ Percentage of women who are disempowered

${ }^{\mathrm{b}}$ Percentage of women who are empowered

${ }^{\mathrm{c}}$ Percentage of domains in which disempowered women are lacking

${ }^{\mathrm{d}}$ Percentage of domains in which disempowered women are empowered

${ }^{\mathrm{e}}$ Percentage of women who do not have parity with index man in the household

${ }^{\mathrm{f}}$ Percentage of women with parity

${ }^{\mathrm{g}}$ Average gap in empowerment levels of women and men for households that do not have parity

similar to the contribution of the production domain. However, we do note that excessive workload accounts for a greater proportion $(22.0 \%)$ of disempowerment than its weight $(20.0 \%)$ in the cash-cropping group and is just below the threshold for women in the food-cropping group (19.0\%).

\subsection{Women's empowerment in agriculture relative to men}

In comparison to men, women's 5DE scores are lower in each farming system. While men from landless households are disempowered in the five domains (like the women), this is not true for men in food- and cashcropping households. In fact, for the latter two groups, the proportion of men who are empowered are almost twice that of women. Men also have higher average adequacy scores than women in all farming systems.

On average, the proportion of men disempowered in each of the 10 subindicators of the WEAI is less than the proportion of women (results not shown). Figures 2 and 3 indicate that the key contributors to disempowerment for men and women are similar-decision-making, credit, group membership, and workload. It should be noted that although the absolute contribution of the workload subindicator is higher for men in the landless group, relative to men in the cash-cropping group, the percentage contribution is similar. This is presumably because the former also have higher aggregate disempowerment scores than the latter.

When we consider the intrahousehold distribution of men and women with respect to the five domains of empowerment, we find that the proportion of households with both an empowered index man and woman is highest in the cash-cropping group, followed by the foodcropping and landless groups (results not shown). The ranking reverses for households in which both individuals are disempowered. When the index man is disempowered, there are more households with a disempowered woman than an empowered one in every farming system. 
Fig. 1 Percentage of women disempowered in each subindicator

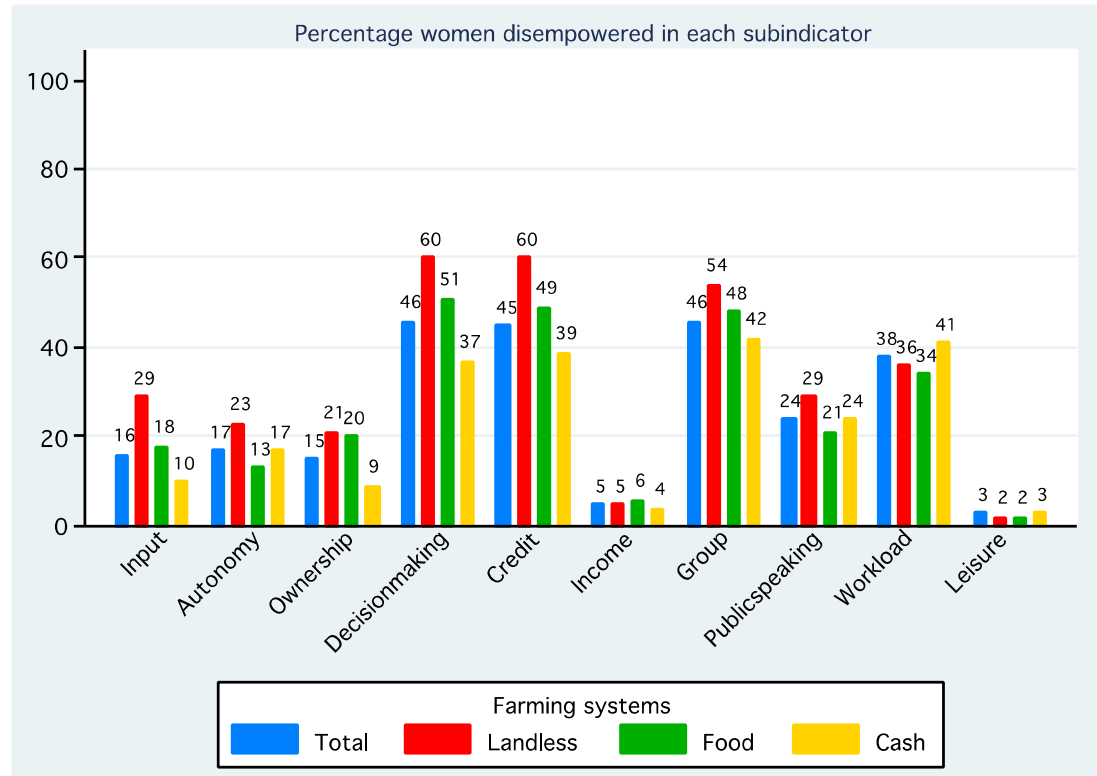

\subsection{Relationship between women's empowerment in agriculture and market orientation of farming systems}

Results for testing the relationship between women's empowerment in agriculture and the market orientation of their respective farming systems, while accounting for individualand household-level variables that could confound the relationship, are presented in Table 4. We see that women's empowerment in agriculture is significantly higher among cashcropping and food-cropping households, relative to the landless households. Further, 5DE scores are higher by 0.086 points for women belonging to cash-cropping households, which is more than double the change found for women belonging to food-cropping households ( 0.039 points).

We also find that indirect measures of empowerment, like age and education, are also significant. As expected, empowerment scores improve as the woman grows older. On the other hand, our results indicate that empowerment scores are significantly lower for women with greater years of education. At the household level, we find that significant determinants of women's empowerment in agriculture include total livestock units owned, access to irrigation, and electricity. Women's empowerment scores are significantly lower as the area of land owned by the household increases. Although
Fig. 2 Absolute contribution of subindicators to disempowerment

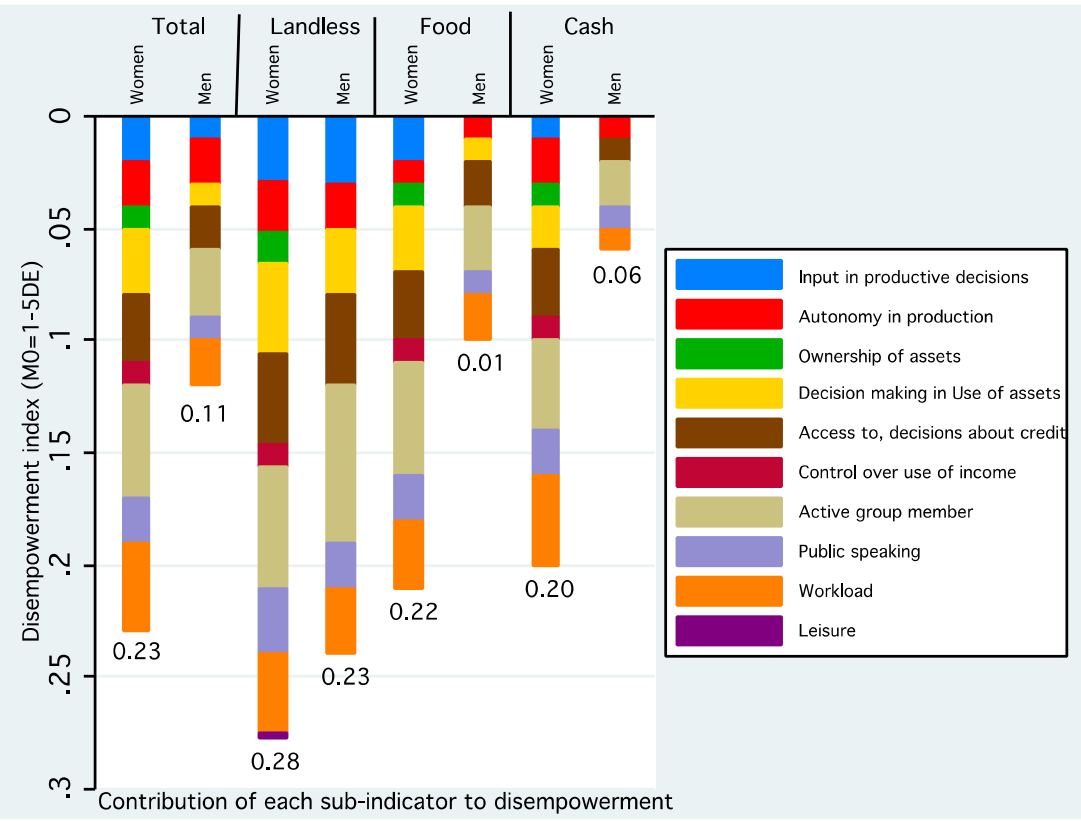


Fig. 3 Percentage contribution of domains to women's disempowerment

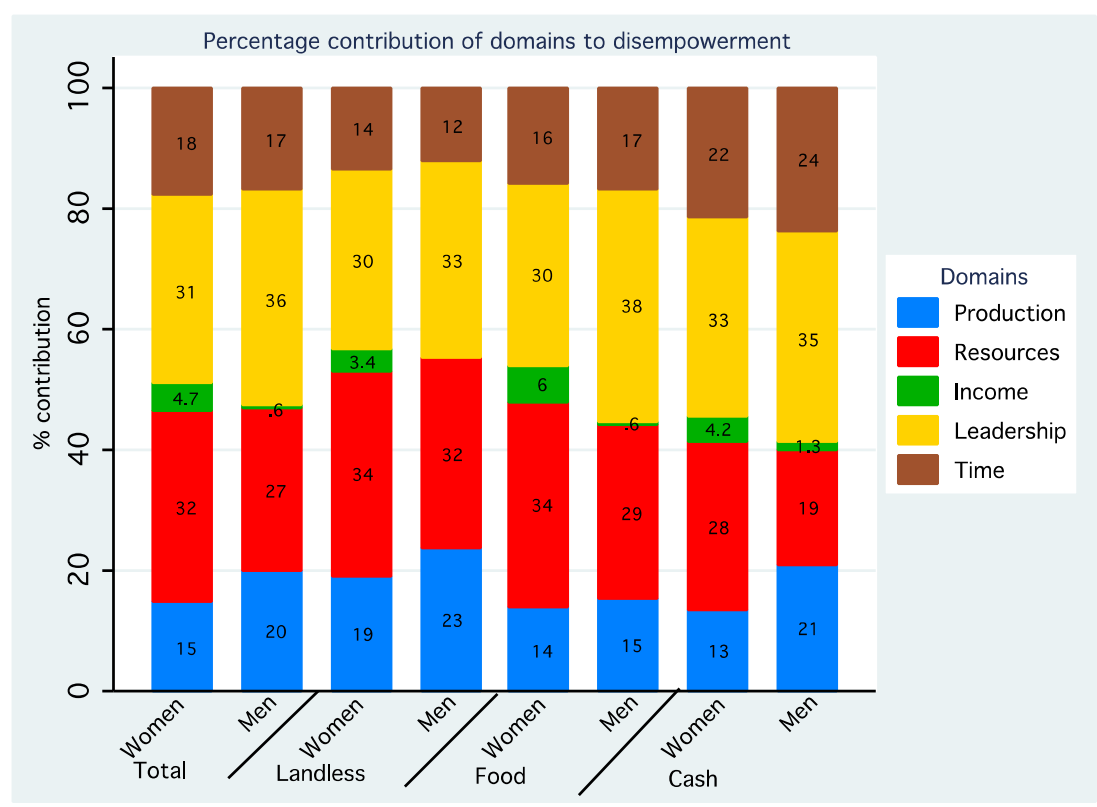

women's empowerment scores also change as the size of the household increases and if the household belongs to a socially disadvantaged caste group, the effect of these two variables is not significant.

\subsection{Comparison against non-agricultural domains of empowerment}

Results from Tables 5 and 6 show the relationship between women's decision-making and autonomy in nonagricultural activities and their empowerment in agriculture for our total sample. We find that women's empowerment in agriculture is significantly associated with both types of outcome variables. The $\log$ odds of a woman having autonomy in decisions related to minor household expenditures, family planning, seeking healthcare, child feeding, and visiting their maternal homes are higher when the woman is also empowered in agriculture, relative to the log odds of a woman being able to make decisions in these domains. The log odds for decision-making and autonomy are also significantly lower as the age difference between the index man and woman increases.

\section{Discussion}

This study is the first to apply and analyze the WEAI in an Indian context. Breaking down the WEAI as the sum of the 5DE and GPI results in some interesting insights. First, the average adequacy of disempowered women can be similar, even when 5DE and WEAI scores are very different. This is true for women in the landless and cash-cropping groups. Second, GPI scores can be similar even when farming systems have

Table 4 Relationship between women's empowerment and farming systems

\begin{tabular}{ll}
\hline & $\begin{array}{l}\text { Women's 5DE score } \\
\text { Coefficient } \\
(p \text { value })\end{array}$ \\
\hline Food-cropping households & $0.039^{+}$ \\
& $(0.054)$ \\
Cash-cropping households & $0.086^{* * *}$ \\
& $(0.000)$ \\
Area of owned plots & $-0.006^{* * *}$ \\
& $(0.001)$ \\
Access to irrigation (binary) & $0.032^{*}$ \\
& $(0.033)$ \\
Age of index woman & $0.035^{* * *}$ \\
& $(0.000)$ \\
Age squared of index woman & $-0.000^{* * *}$ \\
Index woman's education level & $(0.000)$ \\
& $-0.009^{*}$ \\
Household size & $(0.016)$ \\
Total livestock units owned & -0.007 \\
Disadvantaged caste (binary) & $(0.197)$ \\
Access to electricity (binary) & $0.015^{*}$ \\
Constant & $(0.019)$ \\
& -0.026 \\
& $(0.712)$ \\
& $0.040^{+}$ \\
& $(0.058)$ \\
& 0.029 \\
& $(0.852)$ \\
\hline
\end{tabular}

$+p<0.10 ; * p<0.05 ; * * p<0.01 ; * * * p<0.001$ 
Table 5 Relationship between women's empowerment in agriculture and decision-making in non-agricultural domains

\begin{tabular}{|c|c|c|c|c|c|c|}
\hline & \multicolumn{6}{|c|}{ Non-agricultural domains of decision-making } \\
\hline & $\begin{array}{l}\text { Minor HH } \\
\text { expenditure } \\
\text { Coefficient } \\
(p \text { value })\end{array}$ & $\begin{array}{l}\text { Family } \\
\text { planning } \\
\text { Coefficient } \\
\text { ( } p \text { value) }\end{array}$ & $\begin{array}{l}\text { Food } \\
\text { preparation } \\
\text { Coefficient } \\
(p \text { value })\end{array}$ & $\begin{array}{l}\text { Seeking } \\
\text { healthcare } \\
\text { Coefficient } \\
\text { ( } p \text { value) }\end{array}$ & $\begin{array}{l}\text { Child } \\
\text { feeding } \\
\text { Coefficient } \\
(p \text { value })\end{array}$ & $\begin{array}{l}\text { Visiting } \\
\text { mother } \\
\text { Coefficient } \\
\text { ( } p \text { value) }\end{array}$ \\
\hline Woman's 5DE score & $\begin{array}{l}2.393 * * * \\
(0.000)\end{array}$ & $\begin{array}{l}0.670+ \\
(0.063)\end{array}$ & $\begin{array}{l}5.827 * * * \\
(0.000)\end{array}$ & $\begin{array}{l}2.671 * * * \\
(0.000)\end{array}$ & $\begin{array}{l}2.130 * * \\
(0.003)\end{array}$ & $\begin{array}{l}1.521 * * * \\
(0.000)\end{array}$ \\
\hline $\begin{array}{l}\text { Disadvantaged caste } \\
\quad \text { (binary) }\end{array}$ & $\begin{array}{l}-0.624 \\
(0.580)\end{array}$ & $\begin{array}{l}-1.251 \\
(0.139)\end{array}$ & & & & $\begin{array}{l}1.169 \\
(0.131)\end{array}$ \\
\hline Household size & $\begin{array}{l}-0.248 * * * \\
(0.001)\end{array}$ & $\begin{array}{l}-0.071 \\
(0.233)\end{array}$ & $\begin{array}{l}-0.56 \\
(0.793)\end{array}$ & $\begin{array}{l}0.037 \\
(0.669)\end{array}$ & $\begin{array}{l}0.194 \\
(0.127)\end{array}$ & $\begin{array}{l}-0.060 \\
(0.355)\end{array}$ \\
\hline $\begin{array}{l}\text { Index woman's } \\
\text { education level }\end{array}$ & $\begin{array}{l}-0.018 \\
(0.746)\end{array}$ & $\begin{array}{l}0.038 \\
(0.379)\end{array}$ & $\begin{array}{l}-0.134 \\
(0.409)\end{array}$ & $\begin{array}{l}-0.097 \\
(0.123)\end{array}$ & $\begin{array}{l}-0.016 \\
(0.853)\end{array}$ & $\begin{array}{l}-0.064 \\
(0.179)\end{array}$ \\
\hline $\begin{array}{l}\text { Age difference } \\
\text { between index man } \\
\text { and woman }\end{array}$ & $\begin{array}{l}-0.052 * \\
(0.024)\end{array}$ & $\begin{array}{l}-0.036+ \\
(0.056)\end{array}$ & $\begin{array}{l}-0.124 * * \\
(0.007)\end{array}$ & $\begin{array}{l}-0.049 * \\
(0.046)\end{array}$ & $\begin{array}{l}-0.062 * \\
(0.056)\end{array}$ & $\begin{array}{l}-0.026 \\
(0.174)\end{array}$ \\
\hline Constant & $\begin{array}{l}1.870 \\
(0.146)\end{array}$ & $\begin{array}{l}0.942 \\
(0.334)\end{array}$ & $\begin{array}{l}1.605 \\
(0.299)\end{array}$ & $\begin{array}{l}0.285 \\
(0.658)\end{array}$ & $\begin{array}{l}0.695 \\
(0.440)\end{array}$ & $\begin{array}{l}-0.699 \\
(0.454)\end{array}$ \\
\hline
\end{tabular}

$+p<0.10 ; * p<0.05 ; * * p<0.001 ; * * * p<0.001$ different WEAI scores, as in the case of the landless and cash-cropping groups.

Descriptive statistics for the WEAI indicate that aggregate empowerment levels in agriculture improve as market orientation of households increases, i.e., as we go from landless households to food-cropping and cash-cropping households. For some of the subindicators, the proportion of disempowered women reflects the same pattern across farming systems. For instance, the proportion of women who are disempowered in the key drivers of disempowerment - decision-making, credit, and group membership - decrease as household market orientation increases. On the other hand for subindicators like workload, we find that the proportion of women who are disempowered is highest in the cash-cropping households, i.e., households with the greatest degree of market orientation.

Lack of group membership is the greatest contributor to women's disempowerment in agriculture in all three farming systems. Based on focus group discussions and in-depth
Table 6 Relationship between women's empowerment in agriculture and autonomy in nonagricultural domains

\begin{tabular}{|c|c|c|c|c|c|c|}
\hline & \multicolumn{6}{|c|}{ Autonomy in non-agricultural domains } \\
\hline & $\begin{array}{l}\text { Minor HH } \\
\text { expenditure } \\
\text { Coefficient } \\
\text { ( } p \text { value })\end{array}$ & $\begin{array}{l}\text { Family } \\
\text { planning } \\
\text { Coefficient } \\
\text { ( } p \text { value) }\end{array}$ & $\begin{array}{l}\text { Food } \\
\text { preparation } \\
\text { Coefficient } \\
(p \text { value })\end{array}$ & $\begin{array}{l}\text { Seeking } \\
\text { healthcare } \\
\text { Coefficient } \\
\text { ( } p \text { value) }\end{array}$ & $\begin{array}{l}\text { Child } \\
\text { feeding } \\
\text { Coefficient } \\
(p \text { value })\end{array}$ & $\begin{array}{l}\text { Visiting } \\
\text { mother } \\
\text { Coefficient } \\
\text { ( } p \text { value) }\end{array}$ \\
\hline Woman's 5DE score & $\begin{array}{l}2.984 * * * \\
(0.000)\end{array}$ & $\begin{array}{l}2.905 * * * \\
(0.000)\end{array}$ & $\begin{array}{l}3.000 * * * \\
(0.000)\end{array}$ & $\begin{array}{l}3.023 * * * \\
(0.000)\end{array}$ & $\begin{array}{l}3.041 * * * \\
(0.000)\end{array}$ & $\begin{array}{l}2.978 * * * \\
(0.000)\end{array}$ \\
\hline $\begin{array}{l}\text { Disadvantaged caste } \\
\text { (binary) }\end{array}$ & $\begin{array}{l}0.713 \\
(0.453)\end{array}$ & $\begin{array}{l}0.769 \\
(0.421)\end{array}$ & $\begin{array}{l}0.742 \\
(0.439)\end{array}$ & $\begin{array}{l}0.756 \\
(0.426)\end{array}$ & $\begin{array}{l}0.756 \\
(0.429)\end{array}$ & $\begin{array}{l}0.758 \\
(0.427)\end{array}$ \\
\hline Household size & $\begin{array}{l}0.055 \\
(0.465)\end{array}$ & $\begin{array}{l}0.051 \\
(0.501)\end{array}$ & $\begin{array}{l}0.048 \\
(0.520)\end{array}$ & $\begin{array}{l}0.102 \\
(0.180)\end{array}$ & $\begin{array}{l}0.074 \\
(0.333)\end{array}$ & $\begin{array}{l}0.079 \\
(0.296)\end{array}$ \\
\hline $\begin{array}{l}\text { Years of education } \\
\text { of index woman }\end{array}$ & $\begin{array}{l}-0.042 \\
(0.425)\end{array}$ & $\begin{array}{l}-0.020 \\
(0.711)\end{array}$ & $\begin{array}{l}-0.032 \\
(0.548)\end{array}$ & $\begin{array}{l}-0.057 \\
(0.285)\end{array}$ & $\begin{array}{l}-0.038 \\
(0.478)\end{array}$ & $\begin{array}{l}-0.033 \\
(0.531)\end{array}$ \\
\hline $\begin{array}{l}\text { Age difference } \\
\text { between index } \\
\text { man and woman }\end{array}$ & $\begin{array}{l}0.039+ \\
(0.052)\end{array}$ & $\begin{array}{l}0.048 * \\
(0.029)\end{array}$ & $\begin{array}{l}0.056^{*} \\
(0.010)\end{array}$ & $\begin{array}{l}0.045^{*} \\
(0.032)\end{array}$ & $\begin{array}{l}0.050 * \\
(0.020)\end{array}$ & $\begin{array}{l}0.050^{*} \\
(0.019)\end{array}$ \\
\hline Constant & $\begin{array}{l}-2.447 * \\
(0.031)\end{array}$ & $\begin{array}{l}-2.508 * \\
(0.029)\end{array}$ & $\begin{array}{l}-2.583 * \\
(0.025)\end{array}$ & $\begin{array}{l}-2.736^{*} \\
(0.017)\end{array}$ & $\begin{array}{l}-2.690 * \\
(0.020)\end{array}$ & $\begin{array}{l}-2.690 * \\
(0.019)\end{array}$ \\
\hline
\end{tabular}

$+p<0.10 ; * p<0.05 ; * * p<0.001 ; * * * p<0.001$ 
interviews conducted during the formative phase of designing this research, the most common reason cited for this was a lack of time. The majority of women work as agricultural wage labor in addition to tending to their own fields. This factor combined with the time spent on household chores and child care (if any) - both of which are traditionally women's domain-leaves women with little time that can be set aside for group-related activities. To the extent that some of these might require a recurring fee and/or an entrance fee, it is likely to be more prohibitive for landless households relative to the other two groups.

Results from our regression analysis indicate a strong relationship between women's empowerment levels in agriculture and the market orientation of their households. We find that women's empowerment scores are significantly higher among women belonging to the cash-cropping and food-cropping households (relative to the landless households), with the increase for the former being greater than that for the latter. We know from descriptive statistics that the proportion of crops sold and empowerment levels both decline as we move from the cash-cropping to the food-cropping and landless households. To the extent that the proportion of crops sold is an indicator of market orientation of households (and the basis of categorizing households into farming systems), this result indicates that women's empowerment in agriculture improves as the market orientation of the household increases.

We also find that women's empowerment in agriculture declines significantly as area of land owned by the household increases. This is consistent with the conclusions reached by Sproule et al. (2015), that the probability of land being owned by women is lower as the total land area owned by the household increases. This implies that increases in household wealth (in the form of land) are controlled by men, increasing the gender gap in resource control.

Our results suggest that education does not increase empowerment levels. This is surprising, given that women's education has often been used as a tool for enhancing their access to resources and/or decision-making. Kabeer (1999, p. 457) suggests that underlying "rules, norms and practices" can explain why women's education can have differing impacts on their autonomy. In her review of Jeejeebhoy's study from 1997, Kabeer suggested that it is these contextual variables that can explain why women's education was more strongly related to several variables focusing on women's autonomy depending on the context in India's southern state of Tamil Nadu, as compared to the northern state of Uttar Pradesh.

\subsection{External validity}

In this section we compare our results to those from the WEAI baselines carried out in USAID's Feed the Future countries (Malapit et al. 2015). We restrict the comparison to the two
South Asian countries, Bangladesh and Nepal, since they are likely to be the closest to Indian cultural norms and farming systems. Having said that, results from the WEAI baselines might not be entirely comparable to our study, since in Malapit et al. (2015) the former are derived from nationally representative surveys (Bangladesh) and/or regions that specifically represent the Feed the Future zones of influence (Nepal). If we consider the "overall" results from our sample, then we find that group membership, workload, and credit are the top three contributors to women's disempowerment in agriculture. Group membership is also the single biggest constraint to women's empowerment in the two South Asian pilot countries, Bangladesh and Nepal, in particular, while workload comes a close second in Nepal only. Unlike our sample, access to and decisions about credit do not constitute a key constraint for women in Bangladesh and Nepal. Women's lack of decision-making in the use of productive assets is the fourth subindicator identified in this paper, and its contribution to women's disempowerment in Nepal and Bangladesh is relatively lower.

\subsection{Limitations}

In this section we discuss limitations that characterize both our study and the WEAI index, in general. The classification of households by farming systems in our study is limited in that while we take into account production orientation, we do not incorporate actual proportions of crop(s) consumed or sold.

Another set of limitations characterizing our study is the cross-sectional nature of data collection. This has implications not just for the agricultural production patterns over time, but also how engagement in those activities can influence empowerment levels over time. It also restricts us from drawing any causal relationships between empowerment and market orientation of households. Further, we recognize the possibility of recall bias for households that reported agricultural production data for rabi 2013 as opposed to rabi 2014. Additionally, the female demographic for this study was restricted to non-pregnant, non-lactating women of the reproductive age group. Although this was done in order to satisfy requirements of a simultaneous study on women's iron deficiency status (not the focus of this paper), we do acknowledge that results on women's empowerment levels in this case may not be generalizable to women of a different age group or physiological status. We also acknowledge that the data analysis in this paper does not address the potential endogeneity between farming systems, and the total area owned by them and their access to irrigation. From descriptive statistics, we do know that cash-cropping households have larger landholdings, greater access to irrigation, and sell almost all of the crop output that they harvest. While it is possible that the choice of crop cultivated is a function of irrigation and land area, for the Chandrapur District it is also dependent on the soil type. 
From preliminary research activities, we know that cotton is cultivated on black soil while paddy cultivation is undertaken on red soil. Similarly, our work does not address the potential endogeneity between women's empowerment levels and the farming system they operate in. Lastly, the geographic focus on one district in one state of India certainly limits the extent to which data analysis and interpretation can be extended to other locations.

The time-use indicator of the WEAI computed in this paper relies on time spent by men and women in primary activities only. Secondary activities were not considered since that would result in a large drop in the number of observations. However, the Abbreviated WEAI put forth by IFPRI at the time that our data analysis was underway also drops the secondary time-use variable, and we, accordingly, feel that this subcomponent of the WEAI is not expected to influence results significantly. Further, in our study, no observations were dropped, even if the total time for activities was recorded to be less than 24 hours. This likely underestimates the importance of the workload indicator for empowerment in agriculture. It is an underestimate since our primary time use captures time spent on agricultural labor and household chores - the two activities that take up the most of the time of women in this region. Time spent on primary activities was accounted for the basis of the threshold of 10.5 hours specified in the WEAI methodology. Any secondary time use would by definition be activities that happen simultaneously and therefore would add to the time records that we already have.

As with any index, the WEAI, too, is subject to certain limitations. The use of equal weights for each domain, and within each domain, is arbitrary in nature. Further, although there is precedence in the literature for using the domains that the WEAI uses (production, resources, time, income, and leadership), the index assumes that the same activities within those domains will be relevant in different contexts. For instance, the public speaking subindicator lays an implicit value judgment on the same set of three activities - across countries - that an individual is able or unable to speak out in favor of. The response options too are subjective in nature and therefore cannot be "standardized" between individuals. For instance, there might be difference in perceptions about "sufficient" time for leisure activities, not just between men and women but also quite possibly between women belonging to say, different socioeconomic levels or caste groups.

The WEAI index ignores the intensity of work involved in primary and secondary activities. This can be relevant from the point of view of nutritional outcomes. Two individuals might work for the same number of hours in an agricultural field. However, while one of them might spend that time weeding, the other could spend it monitoring hired agricultural laborers. The intensity of work in this case would differ for each.

\subsection{Conclusions and policy implications}

This body of work contributes to the existing literature base by using the WEAI in an Indian setting and by studying its association with the market orientation of households. Women, across degrees of household market orientation, are unable to make decisions regarding use of assets, lack access to credit (and the ability to make decisions regarding its use), and are not members of any community group. We find that women's empowerment levels in agriculture improve significantly as household market orientation increases.

The multidimensional nature of the WEAI enables us to identify a "joint distribution of deprivations," that is, deprivations that an individual faces simultaneously. Results from our study conclude that the domains of group membership, credit, and workload make up the joint distribution of deprivations for women. While women are simultaneously disempowered in these three domains, from formative research conducted in the region we can conclude that the reasons for being disempowered in each of these domains are interlinked. For instance, excessive time spent doing agricultural and household work very often leaves women with little time to join a community group, the most common of these being women's selfhelp groups (SHGs). These SHGs, in turn, are also a common source of agricultural credit (in addition, to being a platform for nutrition education and maternal and child health outreach programs). This suggests that policies aimed at empowering women should take into account both the multitude and simultaneity of deprivations, since decision-making in one domain of agriculture can often be influenced by another domain.

Women's inability to influence the use of productive resources, as well as their time-use patterns are often viewed as "sticky domains," that is, women continue to remain disempowered in these domains, relative to men, even in the presence of enabling factors such as economic growth. This holds true for many South Asian countries including India (World Bank 2011). One explanation for persistent disempowerment of women in domains such as the use of productive resources and time-use is the fact that men and women are able to make decisions to differing degrees. This in turn is largely the result of social norms that shape each gender's access to opportunities such as education and employment, and their abilities to make decisions within the established gender roles.

One example of gendered roles and decision-making is the pattern of land ownership and land use. Kieran et al. (2015) reported that in India almost $90 \%$ of agricultural landholders are men. According to Harper et al. (2014), one way of enabling women to make decisions related to land use is to focus on ensuring women's ability to own (and inherit) land and other assets. Roy (2015) found that despite reform to inheritance laws in India, the likelihood of women inheriting land did not change significantly - largely because families were able to circumvent the requirement by "gifting" land to sons. This suggests that the 
design of such reforms needs to be more water tight in order to ensure that the target beneficiaries (women, in this case) are able to benefit as expected. While land ownership is an important step by itself, Kieran et al. (2015) make the point that, in addition to designing policies to ensure that more women own land, focus also needs to be on allowing women to manage and make decisions regarding those lands.

Recognizing that women are disempowered in multiple domains, either by way of ownership of resources and/or in terms of their ability to make decisions, can strengthen the design of public policy. In India, the National Policy for the Empowerment of Women ${ }^{4}$ announced in 2001 focuses on both the social and economic empowerment of women. Its mandate includes women in agriculture, as well as women's health, nutrition, and sanitation. The Policy identifies SHGs as one of the key institutional mechanisms to achieve its goals. Programs/interventions implemented at the level of SHGs can potentially benefit from the results of the WEAI. We should also note that group membership in the WEAI refers not just to SHGs, but also to civic groups and agricultural producer groups, as well as the village governing body (the panchayat). Such a multitude of groups implies advantages of reduced transaction costs and access to a network of information, ranging from social affairs to agricultural extension services. They are also a reflection of genderspecific inclusion and participation in local activities/affairs.

The strong relationship between market orientation and empowerment levels in our paper suggests that linking women to markets can be a pathway to enhancing their empowerment in agricultural domains. Investing in infrastructure to set up wellfunctioning markets as well as in infrastructure that allows women to access those markets by way of roads and means of transportation can be a first step in this direction. That can be followed up by providing women with information related to market prices, producer companies, and so on, depending on the context. Ensuring their ability to make decisions related to the cultivation of crops and their participation in the sale of those crops, with associated income, can be some areas for which relevant policies can be designed, tried, and studied. Exploring, and accounting for, social norms/ practices that possibly limit women's mobility should be an important component of such policies.

At a methodological level, work in this direction can be taken forward by focusing on analysis that accounts for the endogeneity between farming systems and women's empowerment. At a more conceptual level, it will be interesting to see how our results compare with those from other States in India. Variation in cropping patterns, and therefore the degree of market orientation of households, across the country can potentially offer location-specific insights into which domains hold the greatest potential for addressing women's disempowerment in agriculture.

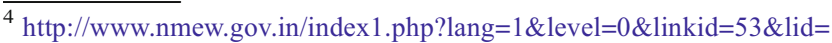
134\&ltypeid $=2 \&$ domid $=10$
}

Funding informationWe thank the Tata-Cornell Institute for Agriculture and Nutrition (TCI) at Cornell University for funding this research.

\section{Compliance with ethical standards}

Conflict of interest The authors declare that there is no potential conflict of interest.

\section{Appendix}

Construction of the WEAI subindices.

The 5DE subindex is calculated for each farming system and accounts for both the percentage of women who are empowered in each group, and the average adequacy level of women who are disempowered. In terms of the M0 matrix, it is represented as shown below:

$5 D E=(1-M 0)=1-H_{d} \times A_{d}=H_{e}+H_{d} \times A_{e}$

In the above formulation, $H_{e}$ and $H_{d}$ are the percentages of women empowerment and disempowered, respectively; $A_{d}$ is the average inadequacy score of disempowered women; and $A_{e}$ is average adequacy score of disempowered women.

In a similar vein, the GPI subindex is also calculated for each farming system and accounts for both, the percentage of women whose $5 \mathrm{DE}$ scores are greater than or equal to those of the index man in their household (i.e., percentage of women who enjoy gender parity) and the gap in women and men's $5 \mathrm{DE}$ scores for women who do not have parity with men. In the following formulation, Pl (adjusted parity gap) corresponds to the original $M 1$ (adjusted poverty gap) matrix.

$G P I=(1-P 1)=1-H_{w} \times I_{p}=H_{p}+H_{w} \times R_{p}$

In the above formulation, $H_{p}$ is $\%$ women with gender parity, $H_{w}$ is \% women without gender parity, $I_{p}$ is women's average empowerment gap relative to men (for women who live in non-parity households), $R_{p}$ is women's relative parity score; $H_{p}+H_{w}=1, I_{p}+R_{p}=1$. A household has "parity" if either the woman is empowered or if a disempowered woman has an adequacy score greater than or equal to that of the man.

Open Access This article is distributed under the terms of the Creative Commons Attribution 4.0 International License (http:// creativecommons.org/licenses/by/4.0/), which permits unrestricted use, distribution, and reproduction in any medium, provided you give appropriate credit to the original author(s) and the source, provide a link to the Creative Commons license, and indicate if changes were made.

\section{References}

Alkire, S., Foster, J., Seth, S., Santos, M. E., Roche, J. M., \& Ballon, P. (2015). Multidimensional poverty measurement and analysis. Oxford: Oxford University Press. 
Alkire, S., Meinzen-Dick, R., Peterman, A., Quisumbing, A., Seymour, G., \& Vaz, A. (2013a). The women's empowerment in agriculture index. World Development, 52, 71-91.

Alkire, S., Meinzen-Dick, R., Peterman, A., Quisumbing, A., Seymour, G., \& Vaz, A. (2013b). The women's empowerment in agriculture index. IFPRI Discussion Paper 01240.

Arimond, M., Hawkes, C., Ruel, M. T., Sifri, Z., Berti, P. R., Leroy, J. L., Low, J. W., Brown, L. R., \& Frongillo, E. A. (2011). Agricultural interventions and nutrition: lessons from the past and new evidence. In B. Thompson \& L. Amoroso (Eds.), Combatting micronutrient deficiencies: food-based approaches (pp. 41-75). Rome and Oxfordshire: FAO and CAB International.

Berti, P. R., Krasevec, J., \& FitzGerald, S. (2004). A review of the effectiveness of agriculture interventions in improving nutrition outcomes. Public Health Nutrition, 7(5), 599-609.

Cunningham, K., Ploubidis, G. B., Menon, P., Ruel, M., Kadiyala, S., Uauy, R., \& Ferguson, E. (2015). Women's empowerment in agriculture and child nutritional status in rural Nepal. Public Health Nutrition, 18(17), 3134-3145.

Cunningham, K., Ruel, M., Ferguson, E., \& Uauy, R. (2014). Women's empowerment and child nutritional status in South Asia: a synthesis of the literature. Maternal and Child Nutrition, 11(1), 1-19.

FAO. (2011). The state of food and agriculture 2010-2011: women in agriculture: closing the gender gap for development. Rome: FAO.

FAO (2005). Livestock sector brief: India. Rome: Livestock Information, Sector Analysis \& Policy Branch, FAO, http://www.fao.org/ag/ againfo/resources/en/publications/sector_briefs/lsb_IND.pdf. Accessed 4 Feb 2015.

GoM. (2000). Report on agricultural census 2000-2001.Maharashtra State. India: Department of Agriculture, Government of Maharashtra.

Haddad, L. (2000). A conceptual framework for assessing agriculturenutrition linkages. Food and Nutrition Bulletin, 21(4), 367-373.

Harper, C., Nowacka, K., Alder, H., \& Ferrant, G. (2014). Measuring women's empowerment and social transformation in the post-2015 agenda. Research report, London: Overseas Development Institute.

Kabeer, N. (1999). Resources, agency, achievements: reflections on the measurement of women's empowerment. Development and Change, 30(3), 435-464.

Kennedy, E., \& Peters, P. (1992). Household food security and child nutrition: the interaction of income and gender of household head. World Development, 20(8), 1077-1085.

Kieran, C., Sproule, K., Doss, C., Quisumbing, A., \& Kim, S. M. (2015). Examining gender inequalities in land rights indicators in Asia. Agricultural Economics, 45(S1), 119-138.

Leroy, J., Ruel, M., Verhofstadt, E., \& Olney, D. (2008). The micronutrient impact of multisectoral programs focusing on nutrition: examples from conditional cash transfer, microcredit with education, and agricultural programs. Innocenti Review 5.

Malapit, H. J., Sproule, K., Kovarik, C., Meinzen-Dick, R., Quisumbing, A., Ramzan, F., Hogue, E., \& Alikre, S. (2014). Measuring progress towards empowerment: women's empowerment in agriculture index baseline report. Washington, DC: International Food Policy Research Institute.

Mapalit, H. J., Kadiyala, S., Quisumbing, A. R., Cunningham, K., \& Tyagi, P. (2015). Women's empowerment mitigates the negative effects of low production diversity on maternal and child nutrition in Nepal. The Journal of Development Studies, 51(8), 1097-1123.

Pinstrup-Andersen, P., \& Watson, D. D. (2011). Food policy for developing countries: the role of government in global, national, and local food systems. Ithaca: Cornell University Press.

Quisumbing, A. R., \& Maluccio, J. A. (2003). Resources at marriage and intrahousehold allocation: evidence from Bangladesh, Ethiopia, Indonesia, and South Africa. Oxford Bulletin of Economics and Statistics, 65(3), 283-327.

Rogers, B. L. (1996). The implications of female household headship for food consumption and nutritional status in the Dominican Republic. World Development, 24(1), 113-128.

Roy, S. (2015). Empowering women? Inheritance rights, female education and dowry payments in India. Journal of Development Economics, 114, 233-251.

Smith, L. C., Ramakrishnan, U., Ndiaye, A., Haddad, L., \& Martorell, R. (2003). The importance of women's status for child nutrition in developing countries. Food and Nutrition Bulletin, 24(3), 287-288.

Smith, L. C., \& Haddad, L. J. (2000). Explaining child malnutrition in developing countries: a cross-country analysis. Research report, Washington, DC: International Food Policy Research Institute.

Sproule, K., Keiran, C., Quisumbing, A., \& Doss, C. (2015). Gender, headship and the life cycle: land ownership in four Asian countries. IFPRI Discussion Paper 01481, Washington, DC: International Food Policy Research Institute.

Sraboni, E., Malalpit, H. J., Quisumbing, A. R., \& Ahmed, A. E. (2014). Women's empowerment in agriculture: what role for food security in Bangladesh? World Development, 61, 11-52.

WEF. (2014). The global gender gap report 2014. Geneva: World Economic Forum.

World Bank. (2011). World development report 2012: gender equality and development. Washington, DC: World Bank.

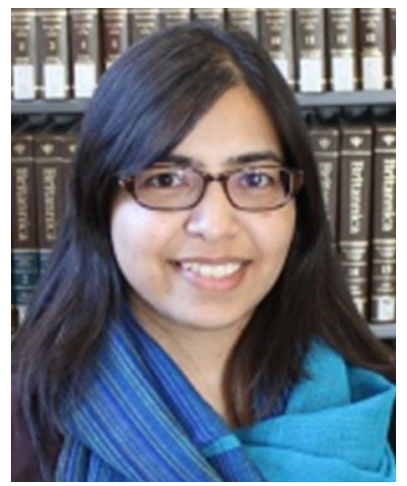

Soumya Gupta Dr. Soumya Gupta is an Economist and Post-Doctoral Associate with the Tata-Cornell Institute for Agriculture and Nutrition at Cornell University. Her research interests lie at the intersections of food security, agriculture and maternal and child nutrition. Dr. Gupta received her $\mathrm{PhD}$ from Cornell University's Dyson School of Applied Economics and Management. She was awarded the inaugural Paula Kantor Award for Excellence in Field Research by the International Council for Research on Women. Dr. Gupta holds a Masters degree in Economics from the Jawaharlal Nehru University and a Bachelors degree in Economics from Delhi University in India. She had extensive research and teaching experience in India prior to joining the TCi. 


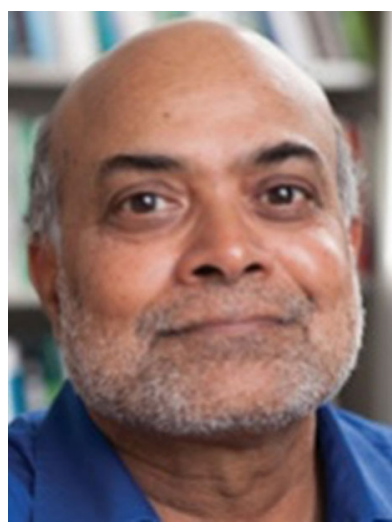

Prabhu L. Pingali Dr. Prabhu Pingali is the Founding Director of the Tata-Cornell Institute for Agriculture and Nutrition, and a Professor in the Charles H. Dyson School of Applied Economics and Management, in the College of Agriculture and Life Sciences, Cornell University. Prior to moving to Ithaca in June 2013, he was the Deputy Director, Agriculture Development Division of the Bill \& Melinda Gates Foundation, based in Seattle Washington, from 2008 to May 2013. Dr. Pingali was elected to the U.S. National Academy of Sciences as a Foreign Fellow in May 2007. He was the President of the International Association of Agricultural Economists (IAAE) from 2003 to 2006. He was elected Fellow of the American Agricultural Economics Association in 2006 and of the International Association of Agricultural Economists in 2009.

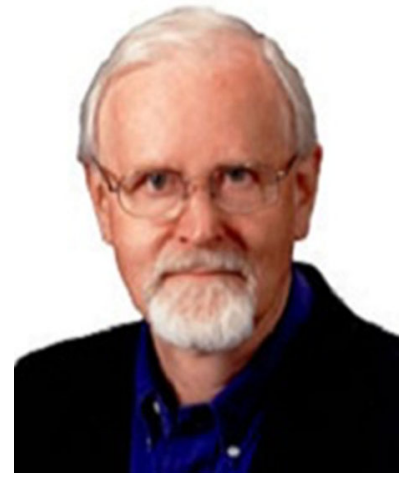

Per Pinstrup- Andersen Per Pinstrup-Andersen, currently Professor Emeritus and Professor of the Graduate School, was most recently the H. E. Babcock Professor of Food, Nutrition and Public Policy, the J. Thomas C l a r k P ofes s or of Entrepreneurship, and Professor of Applied Economics at Cornell University. He is past Chairman of the Science Council of the Consultative Group on International Agricultural Research (CGIAR) and Past

President of the American Agricultural Economics Association (AAEA). He has a B.S. from the Danish Agricultural University and an M.S. and Ph.D. from Oklahoma State University. He is a fellow of the American Association for the Advancement of Science (AAAS) and the American Agricultural Economics Association. He served 10 years as the International Food Policy Research Institute's Director General; seven years as an economist at the International Center for Tropical Agriculture, Colombia; and six years as a distinguished professor at Wageningen University. He is the 2001 World Food Prize Laureate. 